\title{
A Structural Design of Multilevel Decomposition and Mapping
}

Jeong Ick Lee*

(Manuscript received: Aug, 7, 2012 / Revised: Sep, 27, 2012 / Accepted: Oct, 25, 2012)

$$
\begin{gathered}
\text { 다층 중첩 및 매핑에 의한 구조적 설계 } \\
\text { 이정익* }
\end{gathered}
$$

\begin{abstract}
This paper describes an integrated optimization design using multilevel decomposition technique on the base of the parametric distribution and independent axiom at the stages of lower level. Based on Pareto optimum solution, the detailed parameters at the lower level can be defined into the independent axiom. The suspension design is used as the simulation example.
\end{abstract}

Key Words : Multilevel decomposition(다층 중첩), Independent axiom(독립 정의역), Pareto optimum solution(팔렛토 최적해), Torsional beam axle(비틀림 빔 축)

\section{Introduction}

In the mechanical system, a design configuration that fulfills the mechanical performance requirements such as deflection, stiffness and strength must be necessary in an extensive amount of structural designs. It becomes important that the integrated design is used to obtain a minimum weight structure with maximum or feasible performance based on the conflicting constraints. Thus, the mechanical design must begin with the definition of one or more concepts for system or subsystems and a quantitative specification citing requirements, in a given application environment. The overall problem is broken into a series of related but independently definable parts on the base of logical decomposition, without the vague concepts of system or subsystem definition. Two of the most important inputs to the design process are the performance specification and the definition of imposed constraints. The former sets forth the prospective user's definition of how an acceptable end item will work, whereas the latter defines the physical limitations such as size, weight, configuration and environment that affect the mechanical interfaces. Given sets of specifications and constraints as well as one or more concepts for mechanical system, the idealized design process proceeds into the preliminary design phase. And an important aspect of the design process is that of design reviews shown in Fig. 1. Their purpose is to reduce risk associated with the 
introduction of new or improved products into the production. Generally, structural properties have either local design variables or global design variables in each design stage. In local design variables, the detailed dimensions of subsystems are used to generate the intermediated structural properties ${ }^{(1,2)}$. In global design variables, structural properties are themselves used as the design variables ${ }^{(3-6)}$. However, for the computational and decisional efficiencies, both types of design variables must have the feasible limitations at the number and region. The local and global design variables are interrelated in an integrated optimization procedure for incorporating dynamic and structural performances. At each stage, the structural design variables and constraints are interrelated to the sequential optimization procedure $^{(7-8)}$. As the function of the component to be designed is examined in more detail and the technical specifications begin to take form, the relative advantages and disadvantages of the suggested concepts can be established and weighed. Therefore, a multilevel decomposition and parametric trade-off analysis based on the actual dimensions are performed in order to develop the interrelations between variables. The detailed parameters are treated by the independent axiomatic design within the robust region of each parameter.

This paper explains the applicability of aforementioned methodology through the suspension design.

\section{Parametric Distribution}

The parametric distribution region is used to find the detailed parameters. No solution $Y, Z$ exists that minimizes all the $k$ objective functions simultaneously. Thus, using Pareto optimum solution, if there exists no other feasible solution such that

$$
\begin{aligned}
& f_{(k)}(Y) \leq f_{(k)}\left(Y^{*}\right) \\
& f_{(k)}(Z) \leq f_{(k)}\left(Z^{*}\right)
\end{aligned}
$$

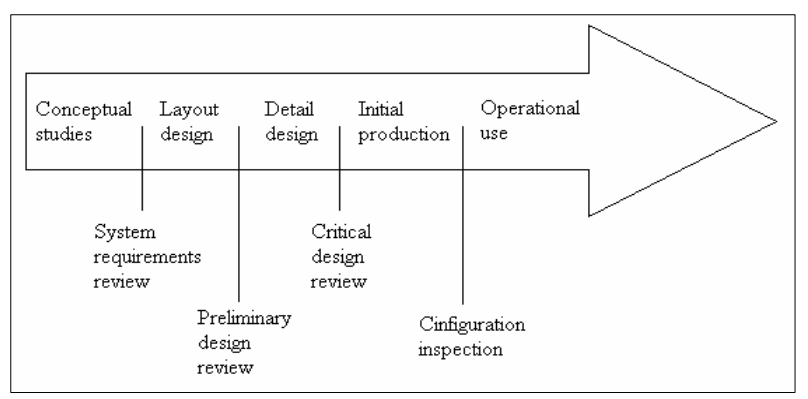

Fig. 1 A typical design review cycle in the feasible region, a feasible solution can be defined as the actually distributed design variables used in the productions. In other words, a feasible solution may productively be called Pareto optimal if there is no other feasible solution that would decrease or increase some objective function without escaping the production region as the robust parametric distribution region. The solution region of design variable is explained in Fig. 2. In the range of $\mathrm{A}$, the objective function sensitively

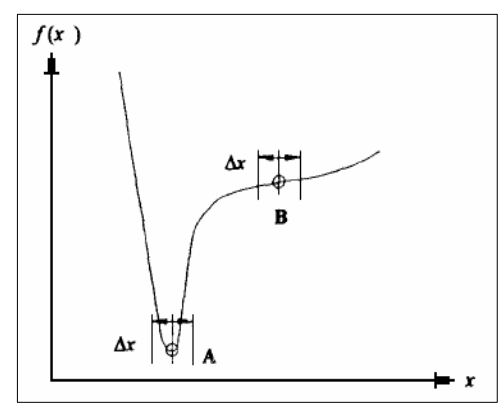

Fig. 2 Design variable region

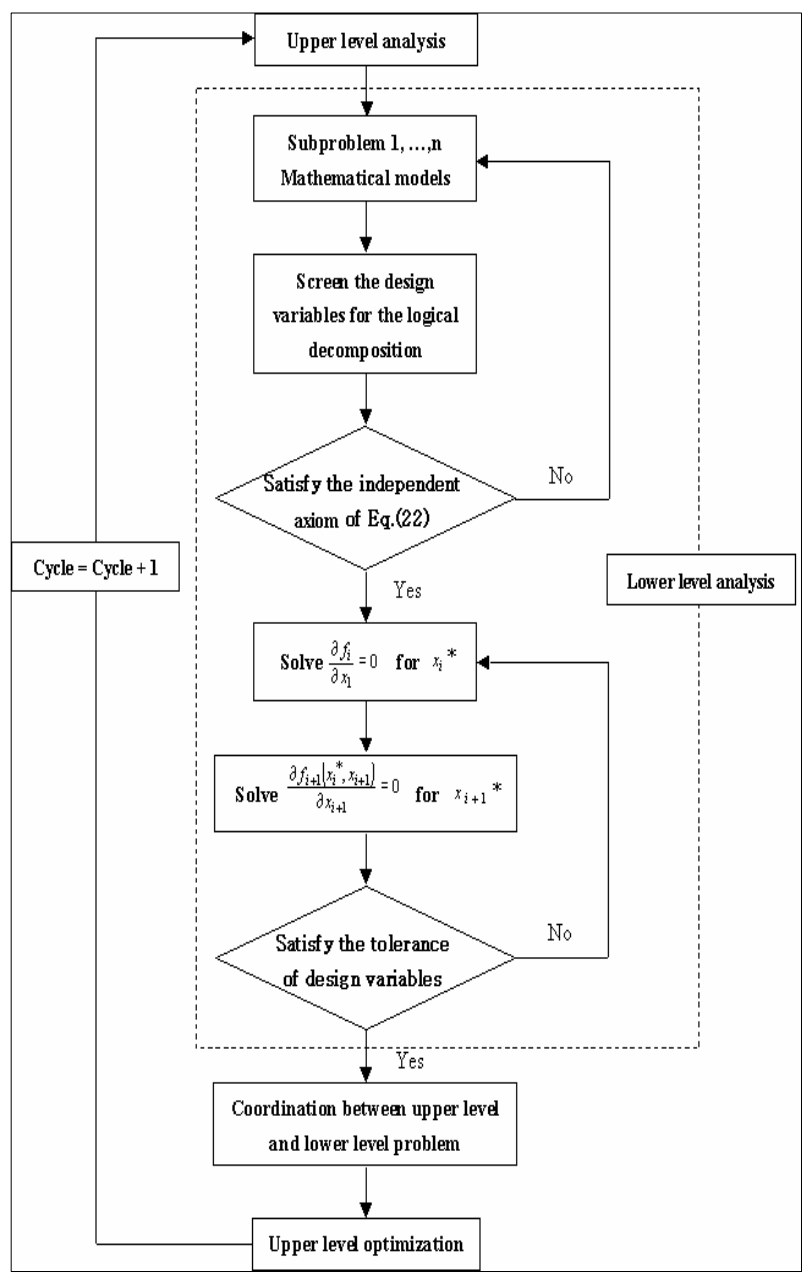

Fig. 3 Combined design process 
changes to the variation of design parameter. In the rage of $B$, the objective function insensibly changes. Thus, in choosing or defining the design parameter, it is necessary that the objective function does not change sharply. These design parameters are considered through the probabilistic effects of design parameters, in relation to the deterministic criterion. The integrated process is shown in Fig. 3.

\section{Simulation}

In the torsion beam axle as example, the kinematic and compliance characteristics are structurally related to the location and section profile of torsion beam and the span from body mounting point to wheel center. The structural strength is estimated by the maximum stress in the welding area and the roll behaviors are related to roll steer and roll camber of suspension, which are important for controllability and stability in cornering. The above factors are influenced by the section design of torsion beam, which are thickness $(t)$, mid line length $(L)$, arc inner radius $(R)$, and sector half angle $(\gamma)$. Fig. 6 shows typical torsion beam axle, which is composed of mounting bushes, spring, shock absorber (S/ABS), trailing arm, mounting bracket, wheel carrier and torsion beam. Fig. 7 shows the torsion beam axle model for the kinematic and compliance analysis. The relationship between twist angle and roll angle can be given on the base of the ratio of torsion beam installation, the span between two body mounting bushes and the span of wheel tread.

$\frac{\phi}{\theta}=\frac{A}{C}+\frac{B}{T}$

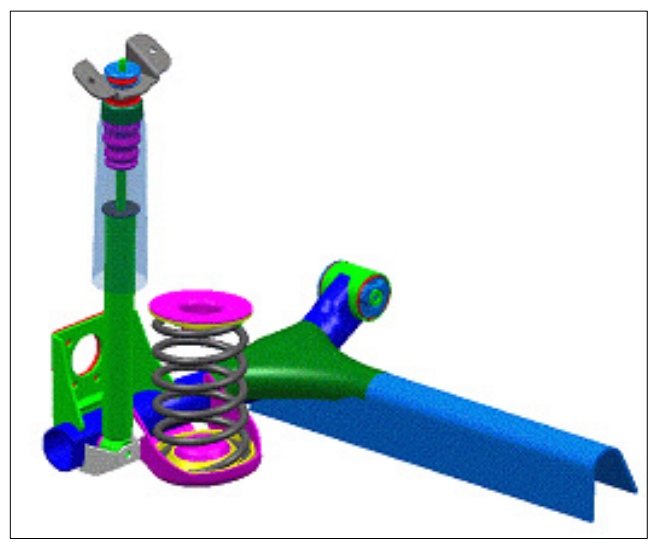

Fig. 4 Torsion beam axle model
In this study, those dimensions concerning the location of Eq. (2) were fixed for only estimating the geometric characteristics of torsion beam. The simulation procedure is shown in Fig. 6. And the schematic model is shown in Fig. 7, which is simulated for the kinematic and compliance analysis. In this analysis, ADAMS is used.

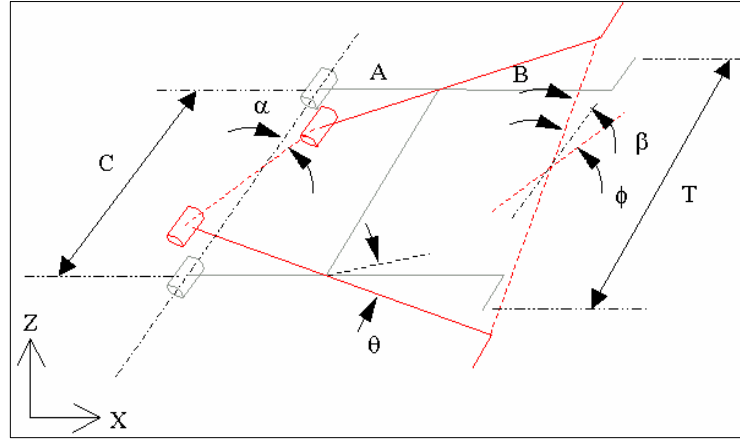

Fig. 5 Torsion beam axle model for $\mathrm{K} \& \mathrm{C}$ analysis

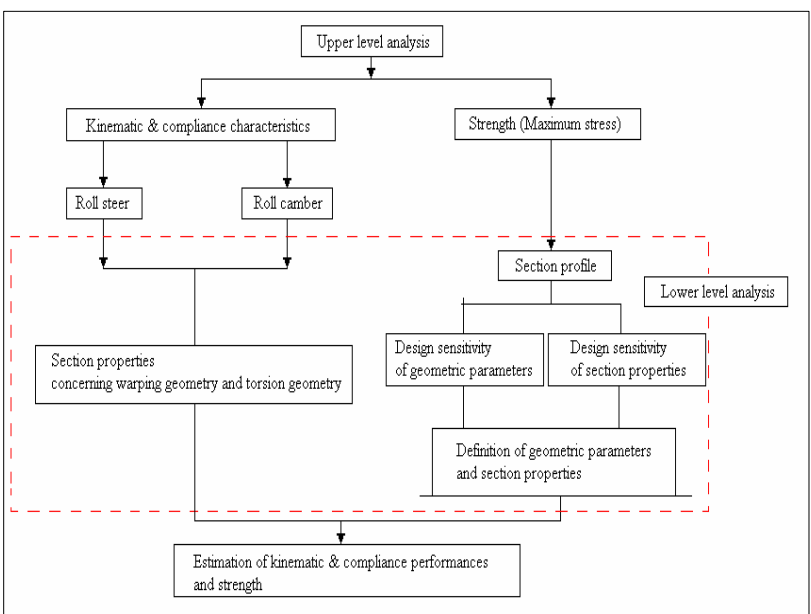

Fig. 6 Design process of torsion beam axle

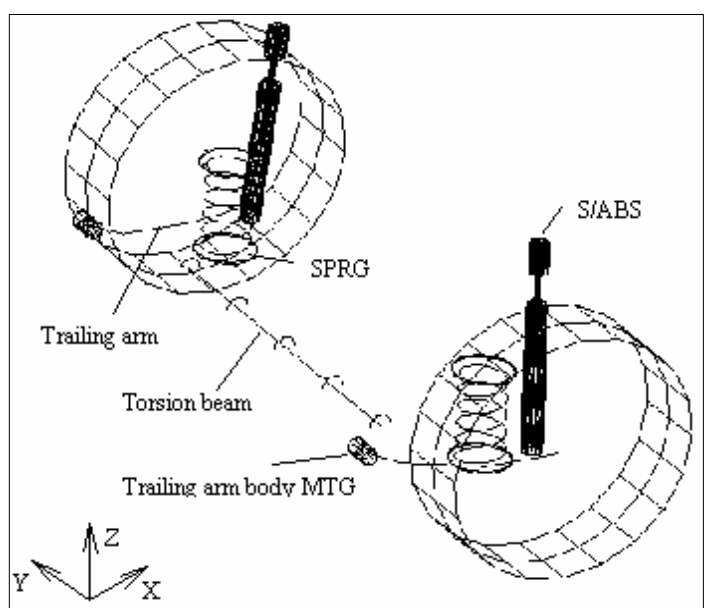

Fig. 7 Schematic model for kinematics of torsion beam axle 


\subsection{Structural performance-strength}

As shown in Fig. 5, a torque is transferred to the torsion beam, under the roll behavior. The transferred torque can be described as the warping and torsional effects given by Eq. (2). The warping and torsional effects bring about the out-of plane mode of section at which the trailing arm is connected. At this welded zone, the stress is concentrated. The transferred torque can be described as Eq. (3).

$$
M_{t}=G K_{\phi} \frac{d \theta}{d y}+E C_{w} \frac{d^{3} \theta}{d y^{3}}
$$

where $M_{t}$ is a torque loaded at torsion beam, $G$ is a shear modulus, $E$ is an elastic modulus, $C_{w}$ is a warping constant and $K_{\phi}$ is a torsional constant given by.

$$
K_{\phi}=\frac{1}{3} \sum L_{i} t_{i}^{3}=\alpha L t^{3}
$$

where $L$ and $t$ are the length and thickness of torsion beam, respectively. $\alpha$ is a shape factor and approaches to 0.33 , in the case that the ratio of $L / t$ is more than 10 .

$$
C_{w}=\int_{0}^{L}\left(\bar{w}_{s}-w_{s}\right)^{2} t d s
$$

where $w_{s}$ represents the doubled sectional area corresponding to the arc $s$ of the middle line of the cross section, given by $w_{s}=\int_{0}^{s} r d s . \bar{w}_{s}$ is the average of value of $w_{s}$. The distance $r$ from the tangent on the arc to the axis of rotation is taken.

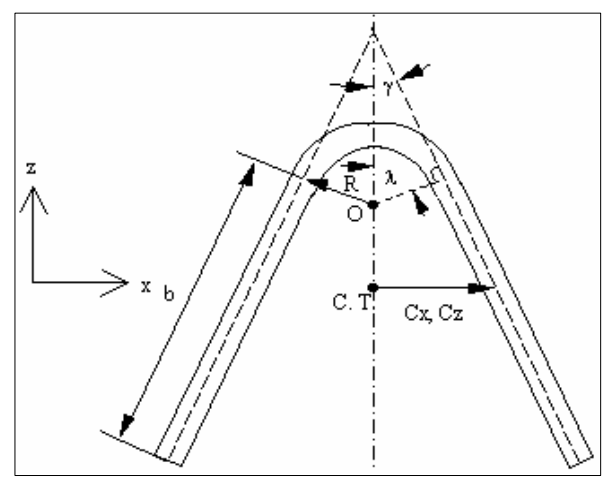

Fig. 8 Section profile of torsion beam
For finding the most important design factor out of the geometric parameters of beam section, the design parameters of section profile are indicated as shown in Fig. 8.

\subsection{Design sensitivity analysis of section parameters}

In order to investigate the effects of geometric parameters on the out-of plane mode (warping mode) as the roll characteristics of torsion beam, the sensitivity analyses were performed. The result of sensitivity analysis is shown in Fig. 11. The section half angle ( $\gamma$ ) is most sensitive to the warping mode of section, relative to the variation of other geometric parameters, which are thickness $(t)$, mid line length $(L)$ and arc inner radius $(R)$.

Also, for investigating the effects of the section properties on the warping mode, the sensitivity analyses were performed. The result is shown in Fig. 10. The torsional constant and warping constant have considerable influences on the warping mode of section.

From Fig. 9 and Fig. 10, the design levels of geometric

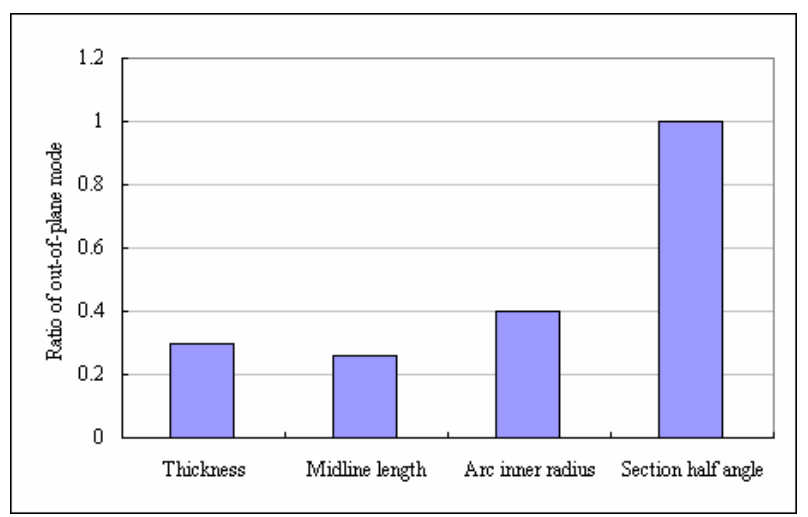

Fig. 9 Sensitivities of section profile parameters to out of plane mode

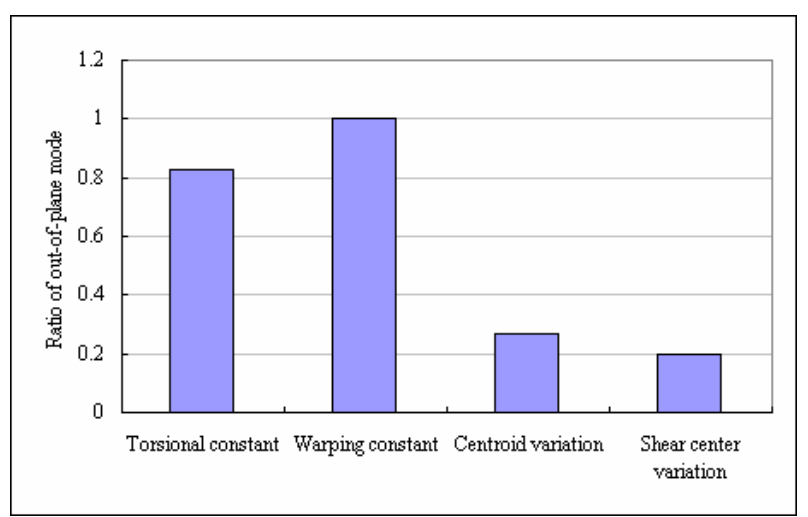

Fig. 10 Sensitivities of section properties to out of plane mode 
Table 1 Levels of design parameters for section geometries

\begin{tabular}{l|c|c|c}
\hline \hline & Level 1 & Level 2 & Level 3 \\
\hline Thickness, $t(\mathrm{~mm})$ & 4.5 & 6 & - \\
\hline Mild line length, $L(\mathrm{~mm})$ & 205 & 207 & - \\
\hline Arc inner radius, $R(\mathrm{~mm})$ & 15 & 25 & - \\
\hline Section half angle, $\gamma(\mathrm{deg})$ & 10 & 20 & 30 \\
\hline
\end{tabular}

Table 2 Section properties of torsion beam

\begin{tabular}{l|c|c|c|c|c|c}
\hline \hline & Case 1 & Case 2 & Case 3 & Case 4 & Case 5 & Case 6 \\
\hline$t(\mathrm{~mm})$ & 4.5 & 4.5 & 4.5 & 6.0 & 6.0 & 6.0 \\
\hline$R(\mathrm{~mm})$ & 25 & 15 & 15 & 25 & 15 & 15 \\
\hline$\gamma_{(\mathrm{deg})}$ & 10 & 20 & 30 & 10 & 20 & 30 \\
\hline$L(\mathrm{~mm})$ & 205 & 205 & 205 & 207 & 207 & 207 \\
\hline$I_{x\left(\mathrm{~mm}^{4}\right)}$ & $6.65 \mathrm{E} 5$ & $6.64 \mathrm{E} 5$ & $6.63 \mathrm{E} 5$ & $8.82 \mathrm{E} 6$ & $8.80 \mathrm{E} 6$ & $8.79 \mathrm{E} 6$ \\
\hline$I_{z\left(\mathrm{~mm}^{4}\right)}$ & $6.87 \mathrm{E} 5$ & $6.85 \mathrm{E} 5$ & $8.83 \mathrm{E} 5$ & $9.18 \mathrm{E} 5$ & $9.17 \mathrm{E} 5$ & $9.15 \mathrm{E} 5$ \\
\hline$K_{\phi\left(\mathrm{mm}^{4}\right)}$ & 6212 & 6155 & 6145 & 14700 & 14740 & 14650 \\
\hline$C_{w\left(\mathrm{~mm}^{6}\right)}$ & $1.05 \mathrm{E} 8$ & $2.36 \mathrm{E} 7$ & $1.15 \mathrm{E} 7$ & $1.60 \mathrm{E} 8$ & $4.36 \mathrm{E} 7$ & $2.40 \mathrm{E} 7$ \\
\hline
\end{tabular}

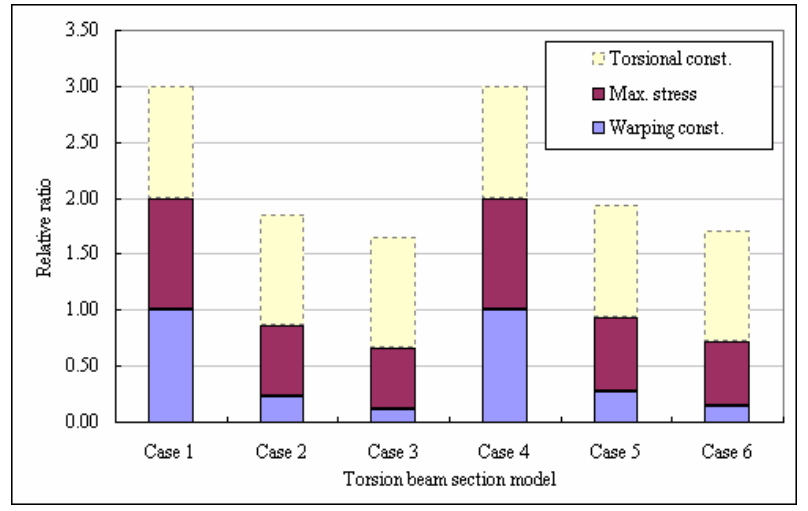

Fig. 11 Stress trends in the welding area

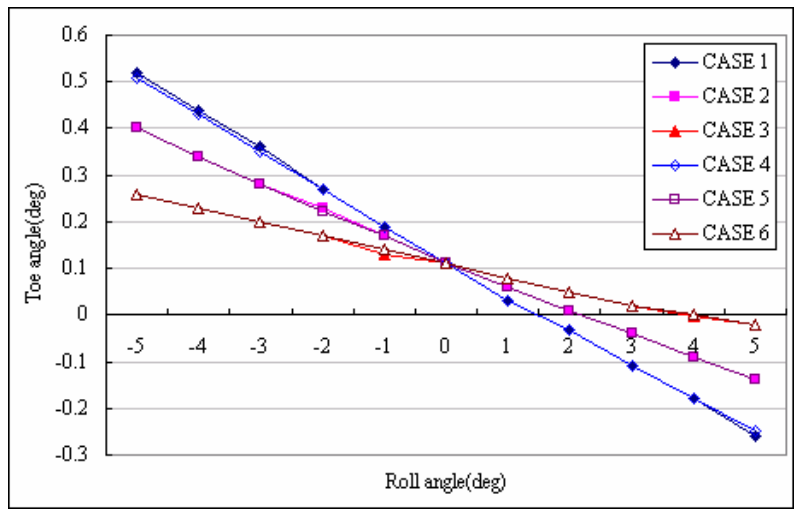

Fig. 12 Toe change of torsion beam axle in roll behavior

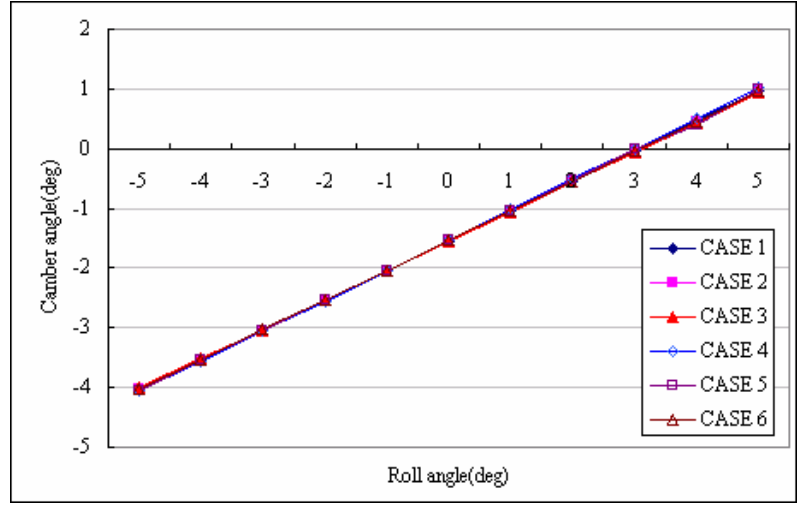

Fig. 13 Camber change of torsion beam axle in roll behavior

parameters and the section properties are chosen as the important design factors of torsion beam. For the independent axiom of the structural strength and roll characteristics, the geometric parameters and section properties are taken into account. The levels of geometric parameters are shown in Table 1 and the section properties of each are shown in Table 2. In the durability aspect, the trend of maximum stress distributed on the welding zone is shown in Fig. 11. It can be said that the warping constant has a great effect on the maximum stress. The toe and camber change as the roll characteristics of suspension are shown in Fig. 12 and Fig. 13. The smaller section half angle and the more warping constant make the toe change larger, while the camber change remains constant. Thus, it can be said that the camber change is affected by the bending mode, which is proportional to the second inertial moment of area, $I_{x}$ and $I_{z}$.

\subsection{Independent axiom and results}

In the kinematic and compliance analysis, the relationship of function requirements with design parameters is defined as,

$$
\begin{aligned}
\left\{\begin{array}{c}
\text { Toe change } \\
\text { Camber change } \\
\text { Warping cons } \tan t
\end{array}\right\}= & {\left[\begin{array}{ccc}
A_{11} & 0 & 0 \\
0 & A_{22} & 0 \\
0 & 0 & A_{33}
\end{array}\right] } \\
& \left\{\begin{array}{l}
\text { Warping cons } \tan t \\
\text { Bending stiffness } \\
\text { Section half angle }
\end{array}\right\}
\end{aligned}
$$

In the structural analysis, the relationship of function requirements with design parameters is defined as, 


$$
\begin{aligned}
\left\{\begin{array}{c}
\text { max imum stress } \\
\text { Warping cons } \tan t
\end{array}\right\}= & {\left[\begin{array}{cc}
B_{11} & 0 \\
0 & B_{22}
\end{array}\right] } \\
& \left\{\begin{array}{l}
\text { Warping cons } \tan t \\
\text { Section half angle }
\end{array}\right\}
\end{aligned}
$$

with the constraint given by,

$$
\begin{aligned}
& \sigma_{\max } \leq \sigma_{\text {allowable }} \\
& \phi^{L} \leq \phi_{\text {roll steer }} \leq \phi^{U} \\
& \psi^{L} \leq \psi_{\text {roll camber }} \leq \psi^{U}
\end{aligned}
$$

where $\sigma_{\text {allowable is the yielding stress of torsion beam material }}$ and is $420 \mathrm{MPa}, \phi$ is the roll steer which is the ratio of toe angle to roll angle and $\psi$ is the roll camber which is the ratio of camber angle to roll angle.

Fig. 14 shows the stress contour under the pothole corner condition of vehicle. The maximum stress on the torsion beam is $330 \mathrm{MPa}$. For the structural analysis, MSC/NASTRAN is used. The initial geometric parameters are given by,

$$
\begin{aligned}
& t=4.5 \mathrm{~mm}, R=25 \mathrm{~mm}, \gamma=10^{\circ}, L=205 \mathrm{~mm}, \\
& I_{x}=6.65 \mathrm{E} 5 \mathrm{~mm}^{4}, I_{y}=6.87 \mathrm{E} 5 \mathrm{~mm}^{4} \\
& K_{\phi}=6212 \mathrm{~mm}^{4}, C_{w}=1.05 \mathrm{E} 8 \mathrm{~mm}^{6}
\end{aligned}
$$

The optimized geometric parameters are given by,

$$
\begin{aligned}
& t=4.5 \mathrm{~mm}, R=25 \mathrm{~mm}, \gamma^{*}=15^{\circ}, L=206 \mathrm{~mm}, \\
& I_{x}=6.654 \mathrm{E} 5 \mathrm{~mm}^{4}, I_{y}=6.878 \mathrm{E} 5 \mathrm{~mm}^{4} \\
& K_{\phi}^{*}=6181 \mathrm{~mm}^{4}, C_{w}^{*}=7.61 \mathrm{E} 7 \mathrm{~mm}^{6}
\end{aligned}
$$

Using the optimized geometric parameters, the maximum stress on the torsion beam is $269 \mathrm{MPa}$. The level of maximum stress is reduced by $18 \%$. The analysis result is shown in Fig. 15.

And as the kinematic and compliance performances under the optimized design parameters, the toe and camber change are shown in Fig. 16 and Fig. 17. The initial roll steer and camber are $-0.08 \mathrm{deg} / \mathrm{deg}$ and $0.5 \mathrm{deg} / \mathrm{deg}$, respectively. The optimized roll steer and camber are- $0.075 \mathrm{deg} / \mathrm{deg}$ and 0.53 $\mathrm{deg} / \mathrm{deg}$, respectively.

The roll steer and roll camber are improved by $6 \%$.

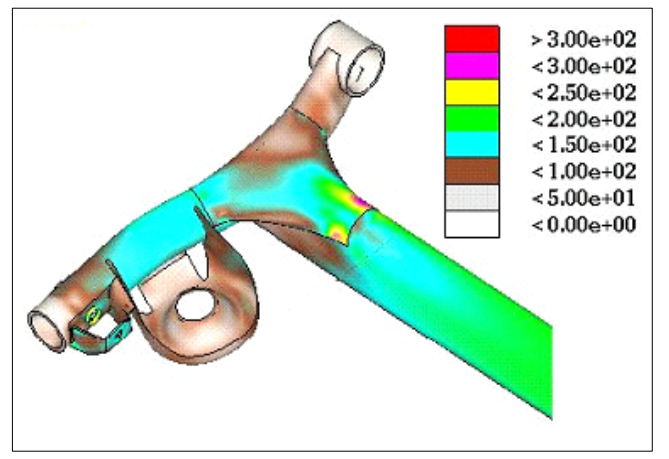

Fig. 14 Maximum stress contour of torsion beam axle(initial)

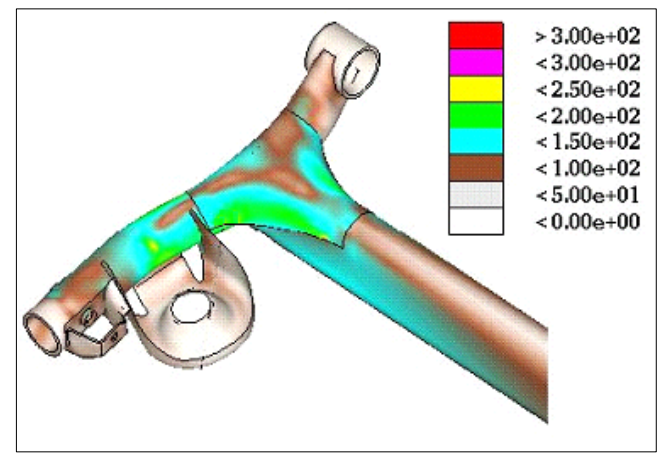

Fig. 15 Maximum stress contour of torsion beam axle(optimized)

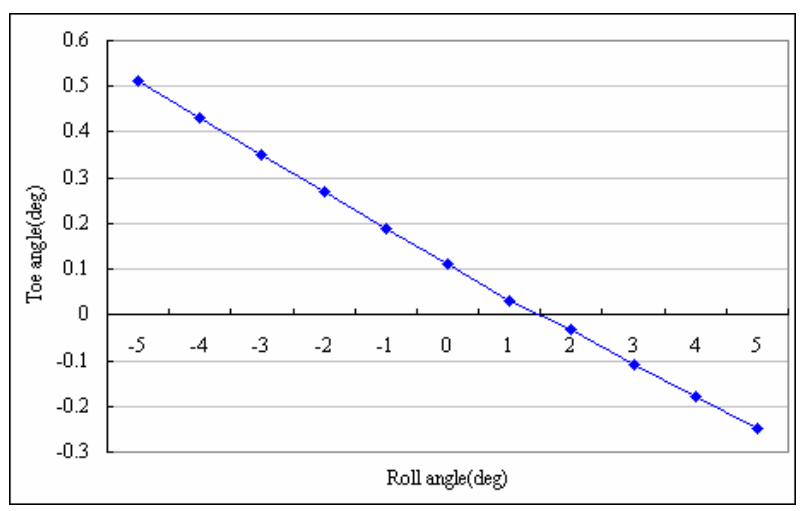

Fig. 16 Toe change of torsion beam axle in roll behavior

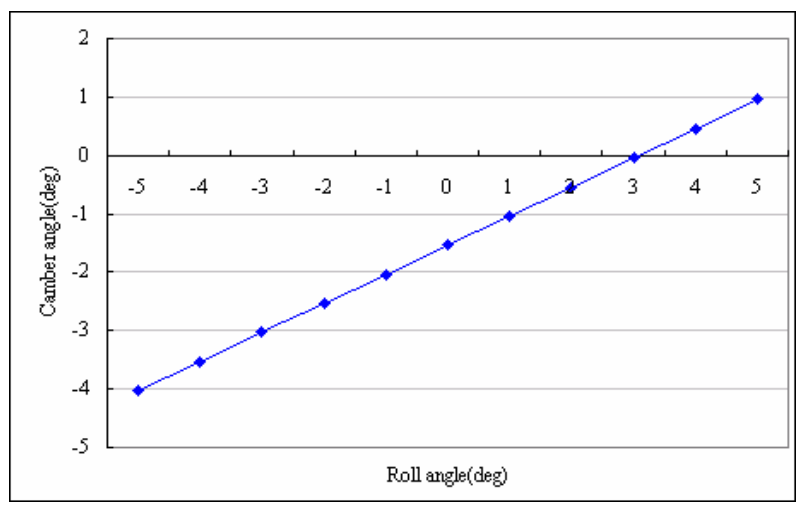

Fig. 17 Toe change of torsion beam axle in roll behavior 


\section{Conclusion}

This paper presents the integrated optimization design using the multilevel decomposition design and axiomatic design.

(1) In an axiomatic design for the optimization design, the uncoupled and decoupled designs between functional requirements and design parameters are generally needed.

(2) Using the design sensitivity (or screening) of design parameters, the approximate uncoupled design is developed on behalf of the decoupled and coupled designs.

(3) Through the hierarchical leveling and approximate uncoupled design, the successive design parameters can be defined on the hierarchical performances.

(4) This method was applied to the suspension of torsion beam axle. The structural performance increases by $18 \%$. The kinematic and compliance performance increases by $6 \%$, within the feasible ranges.

\section{References}

(1) Friedmann, P., and Shantakumaran, P., 1993," Optimum Design of Rotor Blades for Vibration Reduction in Forward Flight," Proceeding of the 39th Annual Forum of the AHS, pp. 1167 1172.

(2) He, C., and Peters, D., 2002, "Optimization of Rotor Blades For Combined Structural, Dynamic, And Aerodynamic Properties," Structural Optimization, Vol. 12, No. 5, pp. 37 44.

(3) Chattopadhyay, A., Walsh, J., and Riley, M., 2001,
"Integrated Aerodynamic Load/Dynamic Optimization of Helicopter Rotor Blades," Journal of Aircraft, Vol. 28, No. 1, pp. 268 273.

(4) Sobieszczanski-Sobieski, J., James, B., and Dovi, A., 1995, "Structural Optimization by Multilevel Decomposition," AIAA Journal, Vol. 23, No. 11, pp. 1775 1782

(5) Sobieszczanski-Sobieski, J., Barthelemy, J., and Riley, K., 1992, "Sensitivity of Optimum Solutions Problem Parameters," AIAA Journal, Vol. 20, No. 9, pp. 1291 1299.

(6) Wrenn, G., and Dovi, A., 1998, "Multilevel Decomposition Approach to the Preliminary Sizing of a Transport Aircraft Wing," AIAA J. of Aircraft, Vol. 25, No. 7, pp. 632 638.

(7) Arora, J. S., and Govil, A. K., 1997, "An Efficient Method for Optimal Structural Design by Substructuring," Computer \& Structures, Vol .7, No. 4, pp. 507 515.

(8) Vanderplaats, G., Yang, Y., and Kim, D., 1999, "Equeational Linearization Method for Multilevel Optimization," AIAA Journal, Vol. 28, No. 2, pp. 290 295.

(9) Kim, H. G., Cho, Y. T., Cho G. H., and Lee, B. H., 1999, "A study on the Structural Design of a Seat Frame in Automotive Vehicles," Proceedings of the Korean Society of Manufacturing, pp. 159 163.

(10) Lee, D, E., Park, S. J., and Han, S. H., 2002, "Sensorless Speed Control of PMSM Superposition Principle," Transaction of the Korean Society of Manufacturing Technology Engineers, pp. 199 205. 